\title{
NOTAS SOBRE FLORA ESPAÑOLA
}

\author{
Pedro Montserrat*
}

\section{SUMMARY}

Notes on Spanish flora. A new variety of Alyssum granatense is made here. Aphanes bonifaciensis is also registered for the first time in Spain.

Centrado actualmente en los problemas planteados por la flora pirenaica, apenas puedo estudiar el abundante material peninsular depositado en nuestro Herb. JACA (herbario del Centro Pirenaico de Biología Experimental). Con todo, conviene divulgar cuanto antes las dos plantas ahora mencionadas, procedentes del centro y sur de España, lejos de nuestro Pirineo.

El estudio del variable Alyssum granatense proporciona una estirpe notabilísima que, por lo menos, merece el rango varietal. La presencia en España de Aphanes bonifaciensis enriquece nuestra flora con una pequeña especie que se consideraba tirrénica.

Alyssum granatense Boiss. et Reuter var Iongipetalum nova var.

A forma typica differt: Anthera minuscula $(0,2-0,3 \mathrm{~mm}$, non $0,5 \mathrm{~mm})$, sepalis acrescentibus magnis (4-5 $\mathrm{mm}$, non $3 \mathrm{~mm}$, longis), stylo longiore (1,5-1,8 $\mathrm{mm})$, nectario minutissimo $(0,2-0,3 \mathrm{~mm})$ circa $1 / 12$ filamenta staminarum; petalis longissimis $(6-7 \mathrm{~mm})$ emarginato-bilobis anguste cuneatis $(0,7-0,8 \mathrm{~mm}$ latis) et filiformibus in $2 / 3$ longitudinis. Silicula magna (5-6 mm) cum pilis stellatis copiosis (6-8 radiatis) et pilis ramosis sparsis cum apice longissimo (1,3-2,2 $\mathrm{mm})$ non applicato. HOLOTYPUS in Herb. JACA (tria specimina), in collibus margoso-gypsaceis, subsalsuginosis, prope Valdemoro del Rey (Cuenca), $780 \mathrm{~m}$ alt. (UTM: 30T-WK2660), P. Montserrat die 15 majo 1968 (n. ${ }^{\circ}$ 1036/68) legebat.

Se trata de una forma notable por sus nectarios diminutos, cortas anteras, pétalos muy largos y estrechos, estilo largo y gran silícula rodeada por sépalos algo acrescentes. Los pelos ramosos del fruto son también España.

(*) Centro Pirenaico de Biología Experimental. Apartado 64. JACA (Huesca), 
muy aparentes. Por sus largos pétalos muy salientes parece apartarse de la próxima var. sepalinum Pomel (cf. MaIre, 1967: 241) de Orán y Argelia.

Vive en la Mancha endorreica de Cuenca, no lejos del Pantano de Buendía, en colinas margoso-yesosas algo salobres, en las fajas de una repoblación con pinos raquíticos, junto a la confluencia del regato de Valdemoro con el río Mayor, no lejos de la carretera de Villalba a Huete. Con ella recolectamos igualmente: Lepidium subulatum, Sisymbrium crassifolium, Ptilotrichum lapeyrousianum, Matthiola fructiculosa, Brassica repanda ssp. nudicaulis, Hippocrepis commutata, Euphorbia nicaeensis, Thymelaea thesiosides, Chaenorrhinum cf. robustum, Fritillaria, cf. hispanica, Trisetum loeflingii, Wangenheimia lima, etc.

Es una especie abundante en España, especialmente en las cuencas endorreicas castellana, aragonesa y manchega, además de Andalucía; algunas formas se extienden a los suelos silíceos erosionados del oeste español. Nuestra variedad se distingue pronto de las estirpes andaluzas de fruto grande (var. granatense), por los pétalos y sépalos más largos.

Conviene recolectar mayor número de ejemplares en otras poblaciones manchegas, estudiando su variabilidad, ecología, dispersión y la posibilidad de crear con ella una subespecie bien caracterizada.

Aphanes bonifaciensis (Buser in Briq.) Holub (1970), Preslia 42: 90-94.

Alchemilla microcarpa Boiss. et Reuter ssp. bonifaciensis Buser in Briq. Prodr. Fl. Corse (1913) 2(1): 204, et var. bonifaciensis Briq. 1.c.: 203 (f. leiocarpa et f. trichocarpa Buser).

El trabajo de Auquier, Duvigneaud y LAmbinon (1974) junto con el estudio del número 5991 (procedente de Córcega), de la Sociedad de Intercambio, nos hizo revisar los ejemplares determinados en Herb. JACA como A. microcarpa. Dos recolecciones españolas se apartan del resto para entrar perfectamente en la variabilidad de la planta tirrénica; una se recolectó cerca de Toledo y la segunda en Despeñaperros.

El ejemplar único toledano, extraordinariamente ramoso desde su base, fue recolectado en la finca del señor Crespo, confluencia del Guadarrama con el Tajo, aproximadamente a $460 \mathrm{~m}$ de altitud (UTM: 30S-VK0016), suelo arenoso de arcilla muy dispersa que determina encharcamientos efímeros en las pequeñas depresiones, dehesa con pasto entre cultivos. Con ella recolectamos también: *Rumex tingitanus, Bufonia tenuifolia, Loeflingia hispanica, Malcolmia patula, *Sedum caespitosum, *Ononis crotalarioides, Trifolium gemellum, $T$. hirtum, ${ }^{*} T$. cf. vesiculosum, $T$. cherleri, Trigonella polyceratia, Scorpiurus subvillosa, Helianthemum ledifolium, Eryngium tenue, Linaria spartea, L. saxatilis, Valerianella coronata, V. discoidea, Vulpia gr. uniglumis, junto con varia ruderales y arvenses. En las depresiones con mayor humedad: Herniaria glabra cf. ssp. nebrodensis, Spergularia cf. purpurea, Trifolium ornithopodioides, T. striatum, Biserrula pelecinus, etc. Herb. Jaca n. ${ }^{\circ} 1714$, leg. P. Montserrat, 2-V-1963.

$\left(^{*}\right)$ Plantas interesantes que convendría comentar. 
Los ejemplares andaluces proceden de la provincia de Jaén, Despeñaperros, collados que bordean el Barranco de Valdeazores, hacia los $900 \mathrm{~m}$ de altitud (UTM: 30S-VH5551), leg. P. Montserrat, Herb. JaCa n. ${ }^{\circ}$ 1741, el 28 de mayo de 1967 (excursión Simposio Flora Europaea). En los rellanos arenosos encontramos otras especies anuales calcífugas como: *Paronychia rouyana, Arenaria leptoclados, Silene gallica, Tuberaria guttata, Lotus conimbricensis, L. parviflorus, Anthyllis cornicina, Trifolium gemellum, T. cherleri, ${ }^{*}$ Coronilla repanda ssp. dura, Aira caryophyllea, Holcus setiglumis, Psilurus incurvus, etc.

Los ejemplares recolectados en ambas localidades presentan el hipanto algo piloso (f. trichocarpa Buser) y acaso difieran de las corsas por su calículo aparente, que puede llegar hasta la mitad de los sépalos; por la forma de sus estípulas, con lóbulos anchos y cortos, no puede subordinarse a A. microcarpa, así como por la tendencia del hipanto a la depilación precoz. Entre todas las microespecies del grupo arvensis es la que presenta frutos más diminutos y sépalos conniventes más cortos.

Los autores belgas mencionados se preguntan si sería más conveniente subordinar, como subespecies, tanto $A$. microcarpa como A. bonifaciensis a una gran $A$. arvensis. Como vemos ahora, las dos de hipanto pequeño resultan simpátridas en España y ambas difieren tanto entre sí como de A. arvensis.

Conviene dirigir el interés de los que trabajamos en flora mediterránea hacia estas microespecies, con razas locales que conviene conocer, tanto por lo que se refiere a su variabilidad morfológica como por lo que afecta a su cariología, ecología y corología.

\section{BIBLIOGRAFIA}

Maire, R. (1967) Flore de l'Afrique du Nord, 13: 238-241. P. Lechevalier. París.

Auquier, P., Duvigneaud, J. y Lambinon, J. (1974) A propos d'Aphanes bonifaciensis distribué antérieurment par la Solciété d'Échange. Société pour l'échange des plantes vasculaires de l'Europe occidentale et du Bassin méditerranéen, fasc. 15: $95-96$ (3 fig.) Liège. 
